\title{
Anesthesia for Mowat-Wilson Syndrome
}

\section{Calhau $\mathrm{R}^{1}$, Santos $\mathrm{C}^{2}$, Marques $\mathrm{J}^{3}$}

${ }^{1}$ Centro Hospitalar de Lisboa Ocidental, Lisbon, PORTUGAL

${ }^{2}$ Centro Hospitalar de Trás-os-Montes e Alto Douro, Vila Real, PORTUGAL

${ }^{3}$ Hospital de Dona Estefânia, Centro Hospitalar de Lisboa Central, Lisbon, PORTUGAL

(Head of department: Dr. José Luís Ferreira)

\section{CASE REPORT}

\section{Past Medical History}

- 15 year-old (25 kg), Mowat-Wilson Syndrome, Hirschsprung disease, epilepsy and mental retardation (ASA III)

- Severe upper gastrointestinal bleeding associated with pyloric stenosis and marked gastric distension

- Proposed for a laparoscopic gastric sleeve and gastrojejunostomy

\section{Physical examination}

- Deep-set eyes, broad nasal bridge, prominent and pointed chin, heavy eyebrows and macroglossia

- No further criteria for difficult airway (DA) - Mallampati I, mouth opening $>3 \mathrm{~cm}$, adequate cervical mobility

- Laboratory results and chest $\mathrm{x}$-ray were normal

\section{INTRAOPERATIVE COURSE}

\section{Airway}

Rapid sequence induction

Plan A succeeded: Cormack I laringoscopy, easy intubation

\section{Breathing}

Volume-controlled ventilation, PEEP

Blood gas analysis $\left(\mathrm{pO}_{2}\right.$ 162-222 mmHg, $\mathrm{pCO}_{2} 34-45 \mathrm{mmHg}$ )

\section{Circulation}

Invasive blood pressure, ultrasound-guided central venous catheter Goal-directed fluid therapy (pulse pressure variation)

Hemodynamic stability without vasopressors, Lactate $0.5-1 \mathrm{mmol} / \mathrm{L}$

\section{Drugs and Maintenance}

Sevoflurane (MAC and BIS guided), Oxygen/Air and Remifentanil Bilateral ultrasound-guided quadratus lumborum block (Ropivacaine $0.375 \% 10 \mathrm{~mL}$ each side), using a $120 \mathrm{~mm}$ needle

Post-operative analgesia (Paracetamol, Ketorolac, Tramadol SOS)

\section{Exposure}

Forced air warming

\section{DISCUSSION}

Mowat-Wilson syndrome is a genetic disease caused by heterozygous mutations of the ZEB2 gene. It is characterized by typical face, mental retardation, epilepsy and variable congenital malformations, including Hirschsprung disease, congenital heart disease, agenesis of the corpus callosum and eye defects. Pyloric stenosis (PS) affects $4.7 \%$ of the patients.

Management of the airway represented our biggest challenge. On one hand, craniofacial malformations could be associated with DA. On the other hand, PS posed a considerable risk of aspiration.

As it would be difficult for the patient to cooperate with an awake intubation we decided for a RSI. However, the DA car, including a fibroscope, was readily available.

Since it was first described by Blanco, QLB has been extensively studied in abdominal and laparoscopic surgery. The lateral approach may generate analgesia from $\mathrm{T} 7$ to $\mathrm{L} 1$, effectively covering all the laparoscopic ports needed for this surgery.

Compared with the TAP block, QLB has proved to result in a widespread and long-lasting effect in laparoscopic surgery.

The clear opioid-sparing effect guaranteed by regional anesthesia is not to be forgotten, considering the systemic nature of the disease.

\section{REFERENCES}

Dshmukh AS, kelkar KV, khedkar SM, gavali Y. Anaesthetic management of mowat-wilson syndrome. Indian journal of anaesthesia. 2016;60(4):292-294.
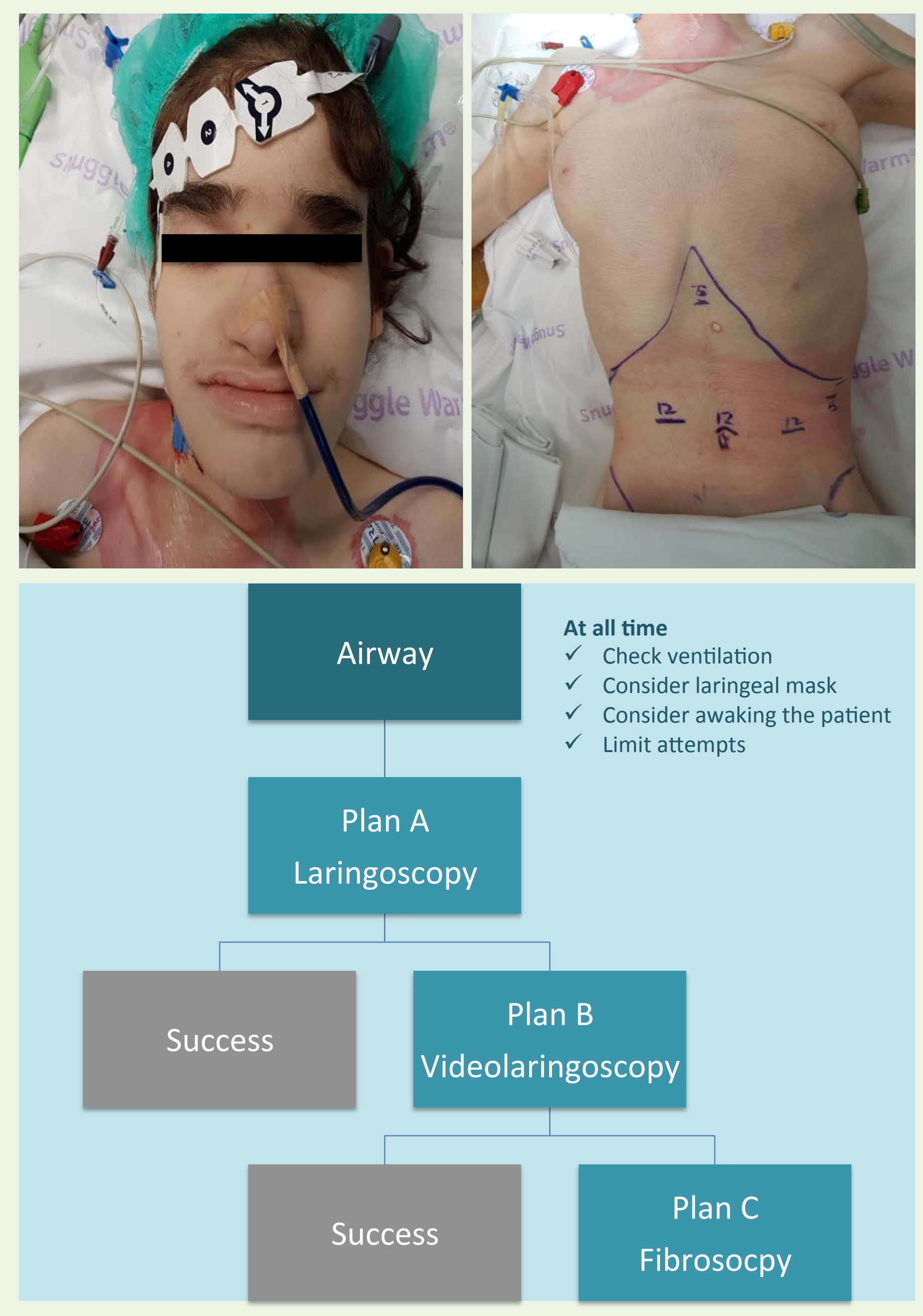

The surgery went on without mishappenings, NB was reversed with Sugammadex $2 \mathrm{mg} / \mathrm{kg}$ and the patient safely extubated.

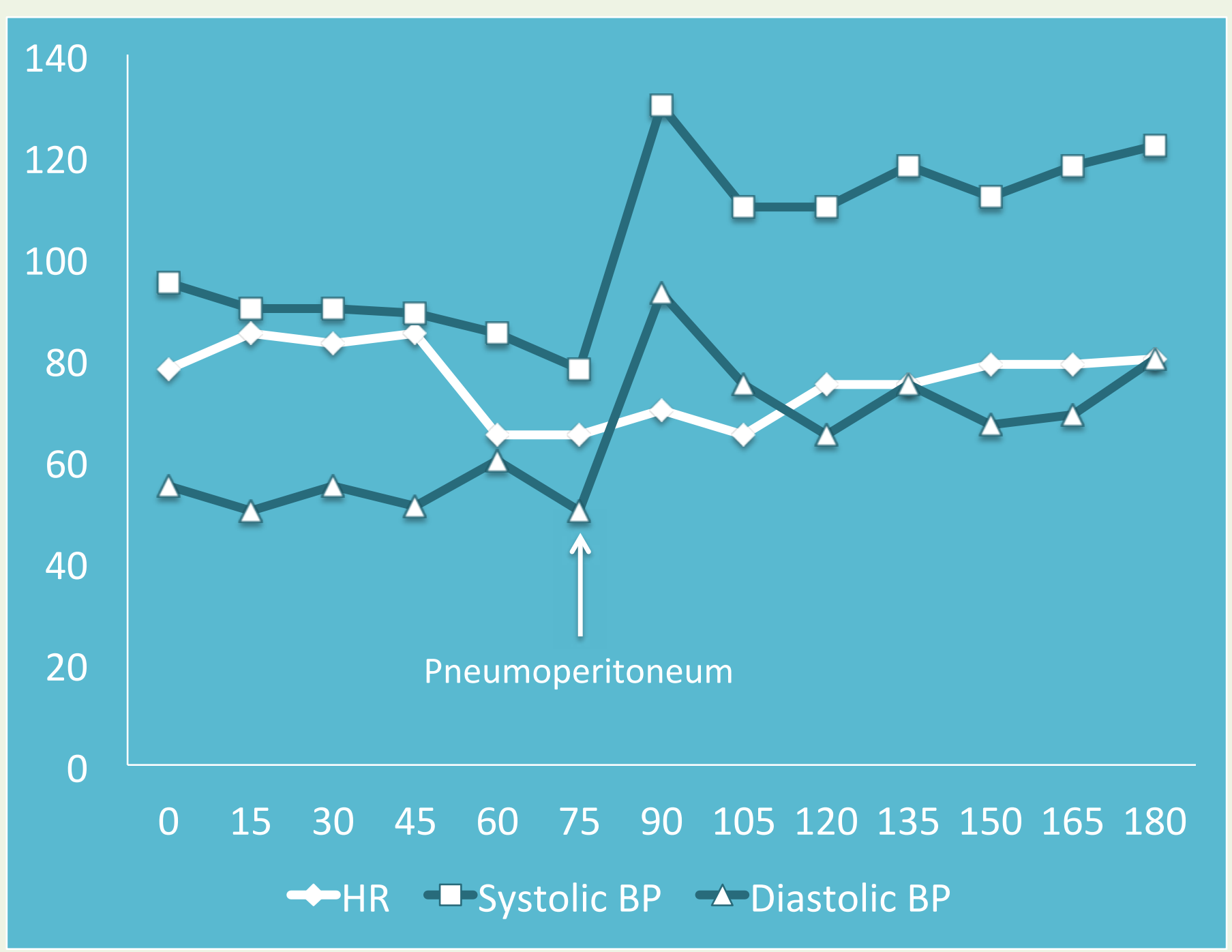

